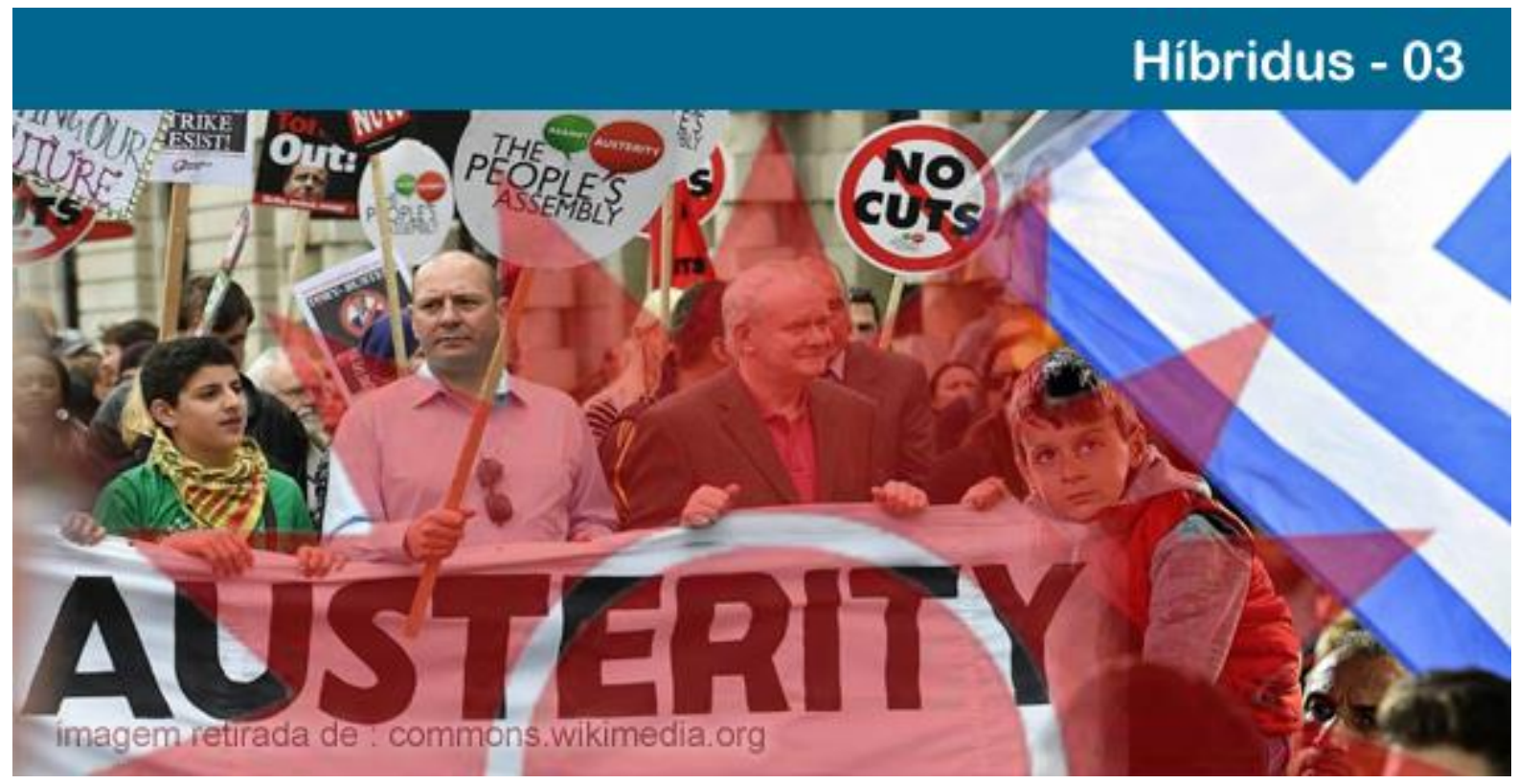

\title{
CONSEQUÊNCIAS PARA A GRÉCIA DA CRISE FINANCEIRA ATUAL E EXPERIÊNCIA ORIGINAL DO SYRIZA COMO 'MOVIMENTO-PARTIDO' QUE SE OPÕE À AUSTERIDADE ${ }^{1}$
}

\author{
Henrique Garcia Pereira \\ Instituto Superior Técnico, Lisboa. E-mail: henrique.pereira@ist.utl.pt.
}

Resumo: O governo de esquerda que tomou posse em janeiro de 2015 na Grécia encontrou o país devastado pelas "medidas de austeridade" impostas pelas instituições europeias para, alegadamente, acabar com a crise financeira. Numa série de ações politico-sociais positivas tendentes a contrariar a deterioração em que o país se encontrava, o SYRIZA trouxe alguma esperança às perspectivas de alteração nas práticas europeias de 'corrigir' a economia dos países periféricos atingidos pelos efeitos do capitalismo globalizado através de um 'receituário' universal.

Palavras-chave: Deterioração da Grécia. Legado do SYRIZA. Resultados positivos.

\section{AFTERMATHS FOR GREECE OF THE CURRENT FINANCIAL CRISIS AND SYRIZA'S ORIGINAL EXPERIENCE AS AN ANTI-AUSTERITY MOVEMENT-PARTY}

Abstract: In January 2015 the Greek leftist government has found a fully disaggregated society by the "measures of austerity" imposed by European institutions in exchange of a pecuniary assistance supposed to put an end to Greece's financial crisis. In an internal struggle against the crisis, SYRIZA has developed a series of popular social-economical practical actions aiming to reduce current deterioration, with positive results. These results are described in some detail, pointing to a new hope on the change of Europe's perspectives when dealing with peripheral countries which can be hit by international political turbulence caused by global capitalism.

Keywords: Demolishment of Greece. SYRIZA’ legacy. Positive results.

\section{Factos e Reflexões}

\footnotetext{
${ }^{1}$ Em caso excepcional, este texto é redigido de acordo com as normas da língua portuguesa lusitana.
} 
Quando o Syriza tomou democraticamente o poder no início de $2015^{2}$, sob a liderança de Alexis Tsipras (um quase-desconhecido na política europeia, $v d$. Fig. 1), encontrou um país devastado e vandalizado pelas 'medidas de austeridade' impostas pela TROIKA ${ }^{3}$ aos países da Eurozona atingidos pela crise do subprime, e cujos governos, em desespero financeiro, apelaram a uma ajuda económica por parte dos seus pares nos países da UE que aderiram ao Euro.

Figura - 1: Poema de Jacinto Lucas Pires (romancista português nascido em 1974) intrigado com (mas encantado por) Tsipras (primeiro ministro grego nascido também em 1974)

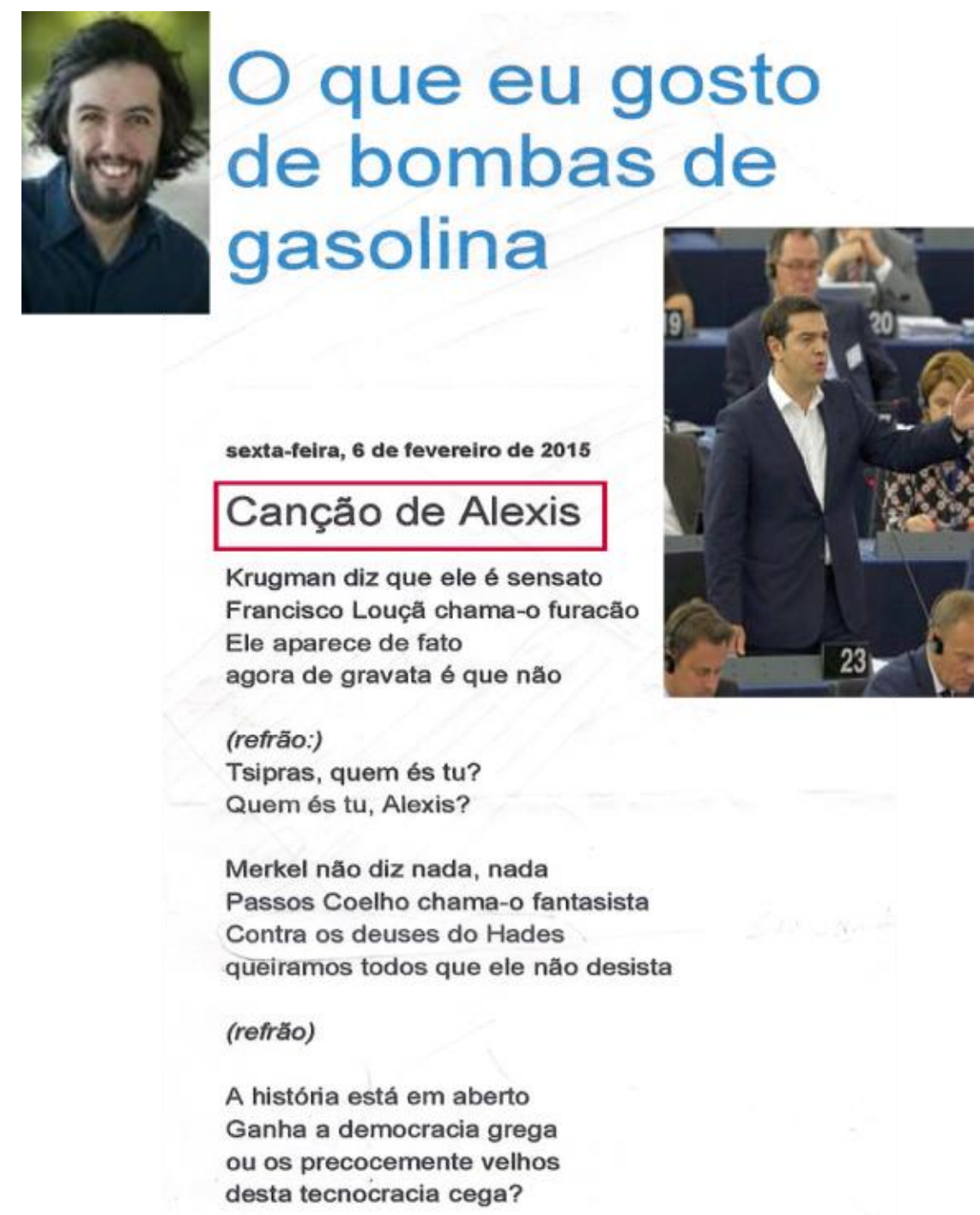

Fonte: Composição do autor sobre poema do blog de Jacinto Lucas Pires.

\footnotetext{
${ }^{2}$ Contrariando a estrofe final (Sem bárbaros o que será de nós? / Ah! Eles eram uma solução) que surge em "À ESPERA DOS BÁRBAROS” de Kaváfis.

${ }^{3}$ FMI (Fundo Monetário Internacional) + Comissão Europeia (Euro-grupo) + BCE (Banco Central Europeu).
} 
As 'medidas de austeridade' trouxeram consigo apenas sofrimento e destruição, sem qualquer dos benefícios anunciados de redução da dívida, crescimento ${ }^{4}$ e prosperidade. Mas o que é exasperante é que as evidências mais básicas desmentem inequivocamente a realidade ficcionada pelos discursos emitidos todos os dias pelos chiens de garde do Establishment (JONES, 2015), a propósito das operações financeiras que iriam 'salvar' o país (e, acima de tudo, a banca internacional) de uma crise causada pelos "gregos preguiçosos que viviam acima das suas possibilidades, maquilhando as contas que apresentavam à Europa" ( $v d$. Fig. 2).

Figura - 2: Operação financeira baseada nas 'medidas de austeridade'

\footnotetext{
${ }^{4}$ A opinião de que os países 'têm' de crescer tem um fundamento claramente capitalista, com origem na Revolução Industrial. Hoje, tornou-se uma banalidade quase terra-a-terra, que só alguns amigos da Terra contestam. Nas sociedades antigas, não existia o 'progresso' que hoje (ou ontem?) era taken for granted (pelo menos, nos países desenvolvidos). Na realidade, estima-se em $0.1 \%$ ao ano a taxa de crescimento económico médio antes dos tempos modernos. A partir do século XIX, surgiu um mundo em que o 'crescimento' económico constante foi suscitado pelos alarmes de algum malthusianismo mal compreendido, que associava a demografia galopante à fome (e assim os alimentos - que, num anacronismo falacioso eram a raison d'être da economia levavam-na ao 'crescimento' ). Nos seus comentários sobre a acumulação primitiva de Marx (que vai a par de um forte 'crescimento' potenciado pelo maquinismo), John Maynard Keynes (1883-1946) defendia a tese de que a tão discutida acumulação primitivas resultou da apropriação, pela Europa, do ouro e prata latino-americanos, em vez de aceitar o argumento sugerido por Max Weber - e amplamente difundido, até hoje - sobre a importância, neste aspeto, da piedade luterana. Na sequência da primeira guerra mundial, surge pela primeira vez a tese de que a recuperação económica (já ligada ao 'crescimento') podia ser atingida através da austeridade para os assalariados, o que veio a conduzir à ascensão do nazismo, na sequência do fracasso da República de Weimar e da Grande Depressão, vista por alguns economistas-teólogos como castigo divino pelos excessos a que uma elite se entregara durante os roaring twenties. Em vez de obrigar os trabalhadores a pagar pelas despesas de Gatsby e seus confrades bons vivants espalhados pelo mundo (o que tem alguma analogia com o que se passa hoje), Keynes desenhou o seu conhecido plano económico, embebido sempre no conceito aristotélico de "vida boa" como o fim último da humanidade ( $v d$. SCHUI, 2014, p. 68, 82, 98).

${ }^{5} \mathrm{O}$ que (não) é de estranhar é que nessa maquilhagem interviesse (a peso de ouro) o Goldman Sachs, grupo financeiro nova-iorquino cujas atividades nefastas na crise financeira mundial polvilham todos os países de onde se pode extrair lucro. Neste banco de investimentos trabalhou Mario Draghi, o presidente do BCE que é suposto 'salvar' a Grécia.
}

\section{POLÊM!CA | Revista Eletronica da Uej}




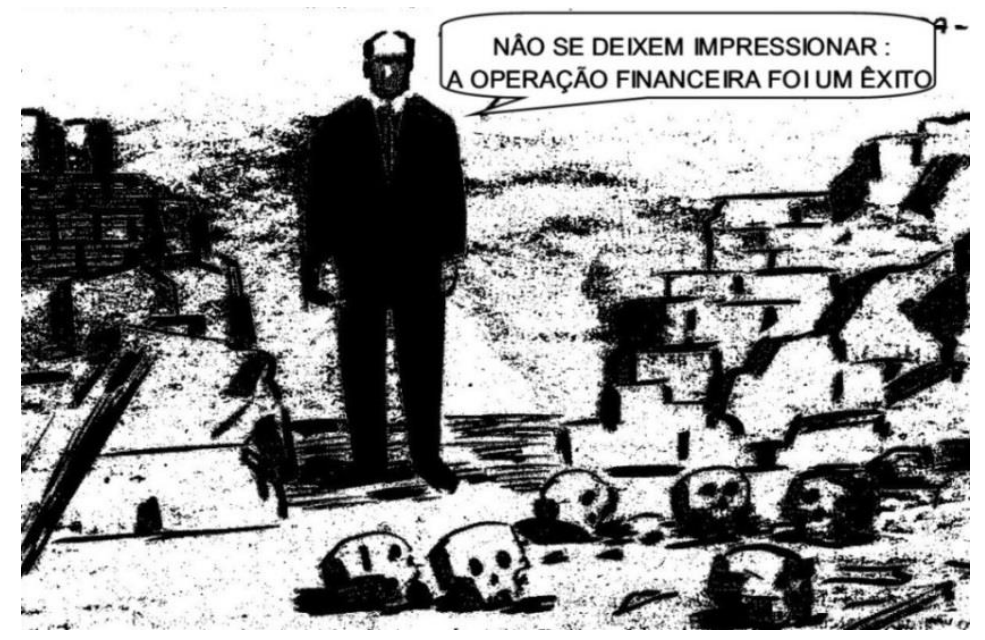

Fonte: Adaptação do autor de uma vinheta de "El País" (02.06.2015).

De facto, em troca de dois 'resgates' (empréstimos que acabavam por beneficiar os credores, especialmente os Bancos Alemães e Franceses que divisavam a seu favor mecanismos financeiros de uma sintaxe incompreensível ${ }^{6}$ ), a TROIKA - desde 2008 até finais de 2014 - impôs à Grécia da Nova Democracia (neo-liberais) + Pasok ('socialistas’) ${ }^{7}$ um programa económico-político que a asfixiou totalmente. Na verdade, o país perdeu $25 \%$ do PIB desde 2010, a população viu reduzido em 1/3 o seu poder de compra, o país importa mais de $70 \%$ dos bens essenciais, depois de - nos anos 90 do século $\mathrm{XX}$ - o sistema económico grego ter sido completamente desmantelado pelo diktat da UE (que controlava o sistema fiscal helénico), a partir de um plano emanado do eixo Alemão-Francês e que consistia em 'especializar os países', deixando para a periferia mediterrânica o TURISMO (e serviços/indústrias de baixo valor acrescentado), e para o centro as empresas de alta TECNOLOGIA e a indústria AGRO-ALIMENTAR. Em consequência, as 'reformas' no

\footnotetext{
${ }^{6}$ Esta sintaxe invoca uma analogia (longínqua, mas irresistível) referente à violência epistémica dos colonizadores ingleses sobre os 'subalternos' (conceito que já surge em Gramsci para generalizar o 'proletariado' para além dos operários fabris), denunciada por Gayatri Spivak a propósito da linguagem usada como instrumento de opressão contra os indianos, no século XIX. Voltando ao presente, verificamos que até o facto de os gregos falarem uma língua 'incompreensível' é uma séria desvantagem, ao terem de expor os seus argumentos segundo a única estrutura admitida pelo 'opressor' (como diz Spivak, 2010, fazer-se compreender através da língua do "outro" é uma tarefa insana).

${ }^{7}$ Estes partidos representam na Grécia o two-party duopoly que tem governado a Europa desde 1945. Trata-se do 'arco da governação' (como é designado em Portugal), constituído por um partido 'de esquerda' ('socialista', trabalhista ou social-democrata) e um 'de direita' (democrata cristão, conservador ou neoliberal). Este 'pequeno' conjunto (cuja soma de votos se aproximava em muitos casos dos 80\%) é designado pela New Left Review como "EXTREME CENTRE", émulo dos Democratas + Republicanos dos Estados Unidos, com as óbvias diferenças que seria de esperar em contextos históricos tão diferentes (ALI, 2015).
}

\section{POLÊM!CA | Revista Eletrônica da Uerj}


mercado de trabalho (flexibilização e precarização) levaram a um desemprego que disparou para $25 \%$, e à terrível circunstância de 30\% das pessoas viverem abaixo do limiar da pobreza, que atinge 1/3 das crianças do país. E a propósito de crianças, não esqueçamos que a polícia (às ordens do governo neoliberal de Samaras) matou um moço de 15 anos (vd. Fig. 3), em 6 de dezembro de 2008 (YOULOUNTAS, 2014, p. 19), no decorrer de uma banal altercação que ocorreu em EXARCHEIA, o bairro mais revolucionário de Atenas (onde a ex-classe operária se mistura com os intelectuais do vizinho POLITÉCNICO, bastião das lutas contra todas as ditaduras).

Figura - 3: Mas as crianças, Senhor... (excerto de um poema que os alunos da escola primária portuguesa sabiam de cor)

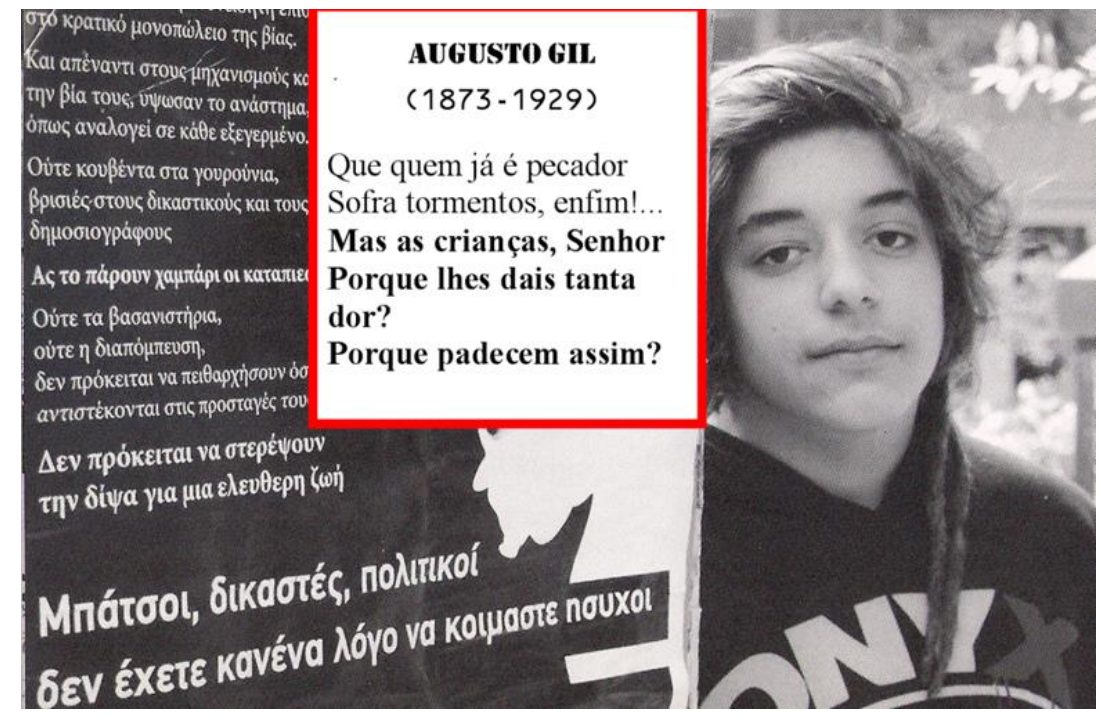

Fonte: Collage do autor. Fotos de Youlountas (2014).

E a austeridade ${ }^{8}$, induzida pelo neoliberalismo à la Hayek, só podia conduzir aos outputs do modelo tachteriano: THERE IS NO ALTERNATIVE ${ }^{9}$ (o que levava a singelas perguntas por parte da 'juventude', $v d$. Fig. 4).

\footnotetext{
${ }^{8}$ Em Portugal, o defensor à outrance da austeridade para os trabalhadores foi o ditador Salazar (sobre cuja tomada de posse Fernando Pessoa dizia: "assistimos à cesarização de um contabilista"), e que levava na verdade um estilo de vida ascético que queria transmitir como exemplo ao País, fazendo depender da 'caridade cristã' a sobrevivência dos 'pobres', de quem se desviava sorrateiramente com uma "ternura de guarda-livros em férias que preferia ter ficado no escritório", como ironiza de novo Pessoa.

${ }^{9}$ Esta questão das alternativas ao pensamento único que o neoliberalismo tenta impor ao mundo globalizado recebeu importantes inputs dos movimentos antiglobalização. Mesmo do ponto de vista epistemológico, a partir da viragem do século XX, estas alternativas foram trabalhadas pelo Fórum Social Mundial, o qual se pode considerar como um produtivo antecessor teórico-prático dos movimentos-partido dos nossos dias. No decorrer deste movimento, estabeleceu-se uma asserção evidente (mas negada pelo Império à la Negri): "OUTRO
}

\section{POLÊM!CA | Revista Eletrônica da Uerj}


Figura - 4: Perguntas ingénuas que a 'juventude' mais cândida não pode deixar de fazer: TANTOS MODELOS DE TÉNIS E UM SÓ MODELO DE SOCIEDADE? COMO É POSSÍVEL?

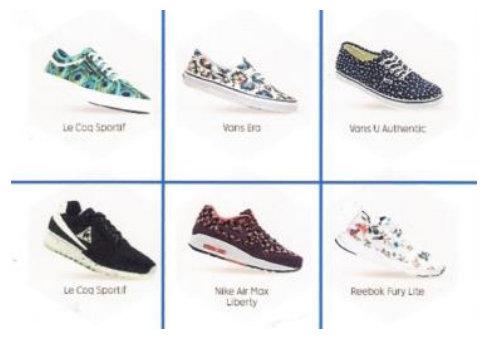

Fonte: Publicidade "Diário de Notícias" (18.07.2015).

Como seria de esperar, o SYRIZA - aglomeração de partidos vindos, segundo a UE, da "extrema-esquerda radical" (e que, juntamente com o PODEMOS espanhol se estabeleceu como ferramenta político-social de tipo novo, $v d$. Pereira, 2015) - opôs-se democraticamente ao pensamento único do neoliberalismo, o qual - por sua vez - substituiu os golpes militares à Pinochet pelos golpes financeiros à Lagarde. E assim, ao mesmo tempo que negociava (ininterruptamente) com a UE+FMI, o SYRIZA prosseguia o seu trabalho de sapa que levava a uma alternativa libertadora do lucro, da predação e da servidão, com base no repúdio pleno da competição e inveja (e na exaltação do pluralismo vivencial). Tratava-se de institucionalizar (na medida do possível) os movimentos espontâneos da sociedade que tentavam minimizar a hecatombe humanitária a que a Grécia estava condenada (e que se assemelha aos resultados de uma guerra, como os intervenientes ainda se lembram amargamente, nas com alguma nostalgia ${ }^{10}$ ). Por isso o Syriza pode ser aqui denominado movimento-partido (como o PODEMOS espanhol ${ }^{11}$ ), na medida em que joga nas duas frentes: por um lado, não descura a manutenção do poder político (com tudo o que isso

MUNDO É POSSÍVEL". De facto, não faz sentido "apreender o mundo, que é uma totalidade inesgotável e diversa, a partir de uma só teoria" (SANTOS, 2005, p. 11, 17, 117).

${ }^{10}$ Afirmam os atenienses que viveram a guerra civil que, hoje, a solidariedade e a entreajuda são quase tão 'sólidas' como no pós-guerra, em que as pessoas compreenderam que precisavam umas das outras. A compreensão deste facto, negado pelos conservadores individualistas, estará certamente ligado aos $n$ milhares (e para $n$, há estimativas de quase dois dígitos, $v d$. Youlountas, 2014) de manifs, meetings, passeatas e ações comuns realizadas desde 2008 contra o Establishment, e que pareciam organizarem-se numa espécie de "EVENT" (ZIZEK, 2014), i.e., num conjunto organizado de pequenas coisas que, num momento mágico, se apresentavam aos olhos de todos como fator decisivo na mudança do modo como vemos o mundo.

${ }^{11}$ Este outro movimento-partido, a partir de campanhas concretas em que envolveu a 'gente' (nomenclatura usada pelo PODEMOS para designar os subalternos), apoderou-se das mais importantes Prefeituras espanholas, em coligações com diversas esquerdas (Madrid, Barcelona, Valencia, Zaragoza, Sevilla, vd. El País, 13.06.2015). 
envolve, a nível executivo ${ }^{12}$ ), e por outro, não abandona o terreno social, lançando movimentos como a "solidariedade para todos", filantrópico - os necessitados, pobres e sem-teto com alimentos e roupas. Na mesma linha, fomenta-se a ideia de solidariedade e amizade assente num comum desejo de fruição, num sentido lúdico, próximo da conceptualização de Huizinga (2003).

E não podemos deixar de enaltecer a importância dos recursos (materiais e humanos) postos à disposição da 'gente' pelos movimentos que iriam dar o SYRIZA aquando do "movimento das praças" de 2011, o ano em que sonhámos perigosamente (ZIZEK, 2012). Tanto a tomada da Syntagma como a da Puerta del Sol induziram (por polinização eletrónica) acampamentos de protesto em muitos terreiros urbanos espalhados pelo mundo (e onde se chegava a cantar o Leonard Cohen, invertendo os termos: "First we take Berlin, then we take Manhattan").

Um outro aspeto, verdadeiramente original, do SYRIZA foi o modo elegante como articulou a democracia direta (exercida nos movimentos sociais) com a democracia representativa (a única reconhecida pela UE). Mesmo na segunda, não há dúvida de que a Grécia deu lições à Europa, com as suas deliberações parlamentares relativas a todos os assuntos importantes, em vez das decisões tomadas ad hoc pelos políticos que mandam na Europa (e às vezes influenciadas pelas combines ditada pelos interesses mesquinhos dos 'representantes' dos países periféricos que querem usar a seu favor o 'castigo' grego, tentando convencer os eleitores de que nenhum partido de esquerda pode tomar o poder e manter-se na UE, $v d$. Fig. 5).

Figura - 5: Nas reuniões quase informais anti-helénicas, o poderoso Claude Juncker (que sabe o que quer, e tem uma ideia clara sobre os jogos de poder na UE) olha pensativamente para as combines entre representantes de

\footnotetext{
${ }^{12}$ Yanis Varoufakis - ministro das finanças do governo Tsipras até meados de julho de 2015 - afirmou numa entrevista a «El País» de 15.05.2015, que, durante cinco meses de duras negociações com a TROIKA, foi raro o dia em que dormiu mais de duas horas...

${ }^{13}$ Muitos outros movimentos sociais são apoiados pelo Syriza, como a Clínica de Solidariedade de Atenas (KIKA), dirigida - para além dos gregos pobres (ou elementos da classe média empobrecidos pela crise) - aos migrantes refugiados (que são em número superior ao dos que demandam Itália). Muitos médicos prestam aí serviço voluntário a tempo parcial, fornecendo também medicamentos gratuitos (num testemunho transcrito no Expresso de 11.07.2015 há uma declaração impressionante por parte de um destes médicos: "estudei com o dinheiro dos contribuintes. Sinto, neste momento, que lhes tenho de devolver". Esta atitude é o contraponto (towards the correct side) da que impera nos países pobres: os técnicos emigram (favorecendo a economia dos países mais ricos) no sentido de ganharem salários desproporcionados, esquecendo a dívida que têm para com a gente que lhes pagou os cursos.
}

\section{POLÊM!CA | Revista Eletronica da deji}


países 'fracos' (cujo conteúdo lhe custa a adivinhar, visto que - ao contrário de qualquer racionalidade manifestam a estranha estratégia de 'enterrar' cada vez mais a Grécia...)

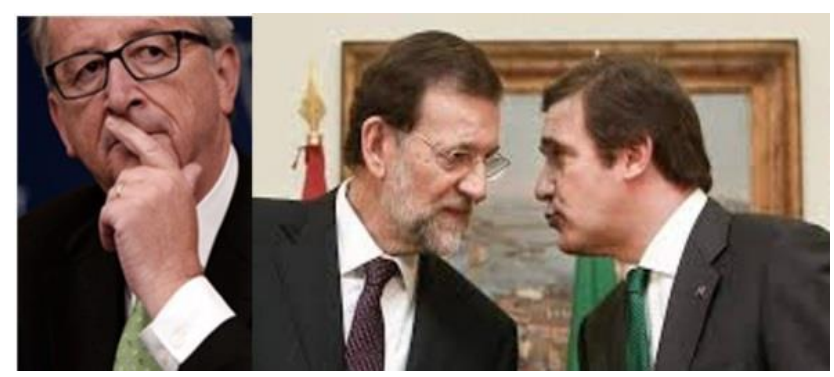

Fonte: Collage do autor sobre figuras do "Expresso" (02.05.2015) e (07.07.2015).

Uma outra conquista do Syriza que lhe dá um estatuto encantador é o facto de o governo grego ter reduzido o IVA para o seu valor mais baixo, para bilhetes de teatro e livros ( $v d$. Fig. 6), o que proporcionou à gente maior facilidade em matar a fome de cultura.

Figura - 6: Teatro e printed matter (dois alimentos para os gregos sem fome de pão)

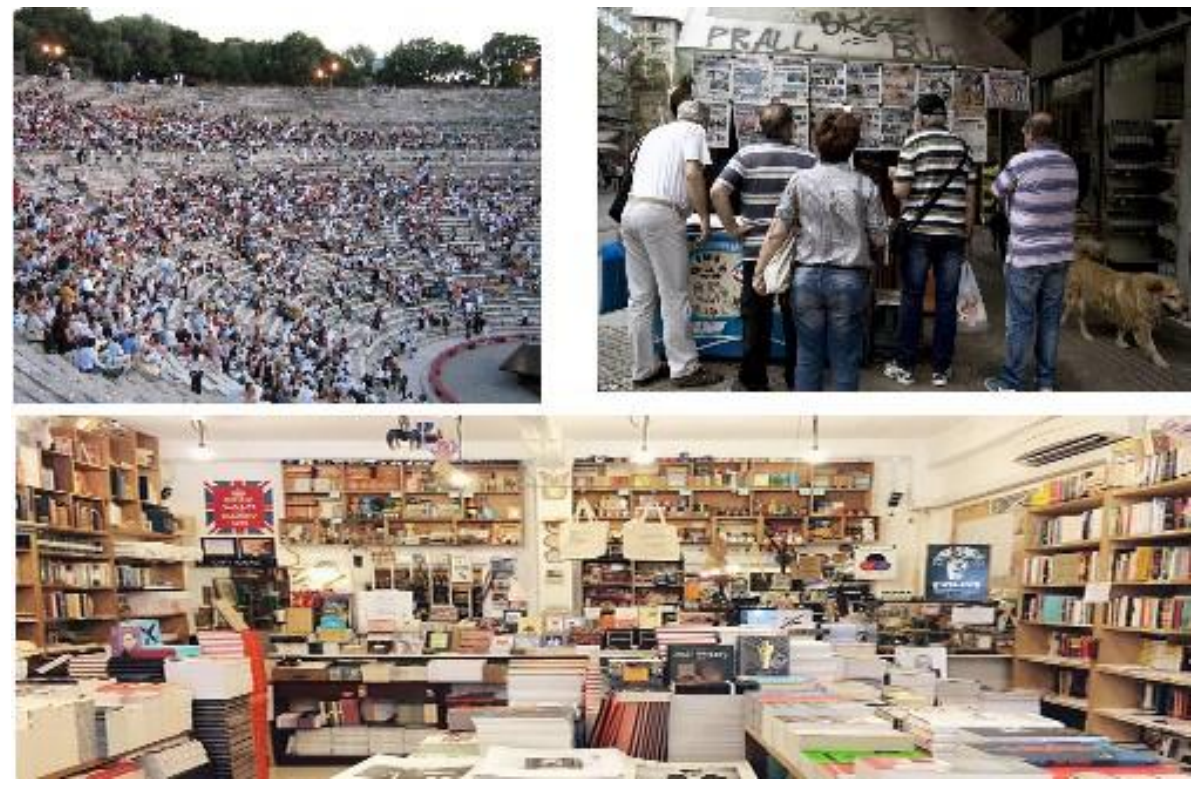

Fonte: Collage do autor sobre figuras do "Público" (12.07.2015).

O que é facto é que, através da sua ligação em rede, apoio técnico e financeiro (retirando 20\% dos salários aos deputados do Syriza), o movimento-partido está (esteve?) envolvido numa miríade de ações humanitárias e culturais com vista a contrariar a austeridade: 
- na sequência do 'desaparecimento' do serviço nacional de saúde (o numero de hospitais que fecha todos os dias não cessa de aumentar, por falta de verba, de medicamentos, de pessoal, de tudo...), o Syriza abriu uma série de dispensários gratuitos (e apoiou clínicas autogeridas);

- no domínio da educação, desenvolveram-se numerosos cursos autónomos e gratuitos (sob a orientação de 'acompanhantes de aprendizagem'), tendentes a despertar nos 'jovens' a paixão de conhecer, estimulando a sua criatividade;

- na 'segurança social'14, criam-se centros de emprego e de ajuda onde, muitas vezes, a troca de serviços e bens se faz sem mediação monetária ${ }^{15}$ (por exemplo, ZIKOS, a mercearia social de EXARCHEIA, recebe as vitualhas dos agricultores e troca-as por objetos mais 'urbanos');

- todos os dias abrem novas pequenas livrarias especializadas (especialmente em política), que são simultaneamente espaços de convívio, solidariedade e criação;

- no bairro de EXARCHEIA, o Syriza incentiva o estabelecimento de vários centros de acolhimento de refugiados e, nas zonas populares, criam-se coletivos em espaços ocupados (como o SINERGIA e o NOSOTROS), verdadeiras ilhas de liberdade e divertimento onde se pode comer gratuitamente, e onde se realizam quotidianamente colóquios, concertos, projeção de filmes alternativos;

- $\quad \mathrm{Na}$ questão dos 'transportes', é de notar que estes foram gratuitos por longos períodos no primeiro semestre de 2015, sendo também retiradas as portagens das autoestradas;

- surgem como cogumelos - tanto na NET como em FM - as "rádio-pirata" e os jornais-panfleto que desconstroem o discurso oficial (por exemplo, a rádio ENTASI, com ligações com outras rádios alternativas no mundo, e o magazine BABYLONIA, onde escrevem Naomi Klein e Raoul Vaneigem ( $v d$. YOULOUNTAS, 2014, p. 50-52).

\footnotetext{
${ }^{14}$ Não esqueçamos que, a 4 de Abril de 2012, um farmacêutico reformado a quem tiraram a pensão de sobrevivência suicidou-se publicamente, deixando uma carta de protesto e de apelo à resistência (YOULOUNTAS, 2014, p. 39)

${ }^{15} \mathrm{O}$ dinheiro, que tudo põe em termos quantitativos, suprime a singularidade qualitativa que é própria do ser humano. Yanis Varoufakis - que era responsável por pagar aos técnicos da TROIKA - propôs ironicamente a cada um deles que o respectivo ordenado (18 vezes superior à média do dos gregos) fosse reduzido drasticamente para respeitar as regras da meritocracia quantitativa capitalista.
} 
Raoul Vaneigem ( $v d$. Fig. 7) - interveniente assaz estimulante no debate ocorrido nos círculos situacionistas de Paris em MAIO 68 (em especial com o seu tão celebrado «Traité de savoir-vivre à l'usage des jeunes générations», de 1967) - continua a refletir agudamente sobre a situação que se vive (vivia?) na Grécia, e a publicar interessantes comentários a propósito das experiências (em que participou) relativas à questão da dádiva ( $v d$. VANEIGEM, 2013)

Figura - 7: Raoul Vaneigem na Grécia de hoje retoma alguns temas de MAIO 68

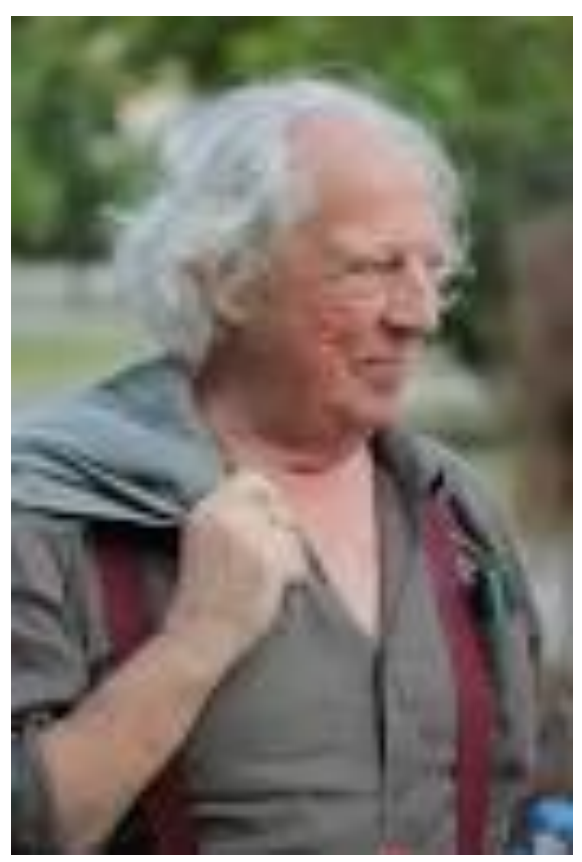

Fonte: Vaneigem (2013, p. 3).

Já que uma (larga) parte das taxas e impostos (bem como os 'empréstimos') são desviados para o casino financeiro controlado pelas mafias internacionais (será isto a economia informal de que tanto se fala?), Vaneigem sublinha veementemente a capacidade autogestionária - baseada na GRATUITIDADE - revelada pelas forças de onde emanou o SYRIZA. Nos coletivos autogeridos de Atenas (e nos centros sociais de solidariedade e da ajuda mútua que se espalham pela Grécia) não há circulação de dinheiro, como se o capitalismo fosse suspenso por instantes em alguns mosaicos espaciais onde se concentra a sua contestação. 


\section{Conclusões (muito provisórias)}

O que se pode talvez deduzir (muito provisoriamente) das reflexões anteriores (já que de factos interpretáveis estamos às escuras em Agosto de 2015), é um aquis que não pode ser desprezado: se a Grécia se tornou o laboratório do totalitarismo financeiro, também é verdade que é o país da Europa onde emergiram as perspectivas mais interessantes no que diz respeito à auto-organização da 'gente', baseada numa dinâmica transiente e não linear, capaz de impelir uma resistência radical às instituições europeias, tanto do ponto de vista político, social e económico. De qualquer modo, a Europa já não é a mesma, depois da 'crise' grega e sua lição de democracia, havendo sinais de que há uma certa mudança no modo como gere a invasão dos refugiados e as manobras financeiras dos bancos chineses.

Nas semanas (meses) alucinantes que duraram os desacordos com o bloco europeu aparelhado pelo sinistro e vampírico 'coronel' Schäuble (ex-leader da CDU até 2000, e hoje ministro das finanças alemão que comanda as tropas da UE, vd. Fig.8) - os negociadores gregos tentaram usar argumentos baseados numa guerrilha retórica baseada na revitalization conceptual praticada por Perelman (1999), mas que embateu retumbantemente contra o rochedo europeu, encarnado pelo master Schäuble, que dita o significado das palavras, segundo o modelo polissémico visto como uma escolha, a que se referia Humpty Dumpty nas conversas com Alice.

Figura - 8: O fácies de Schäuble

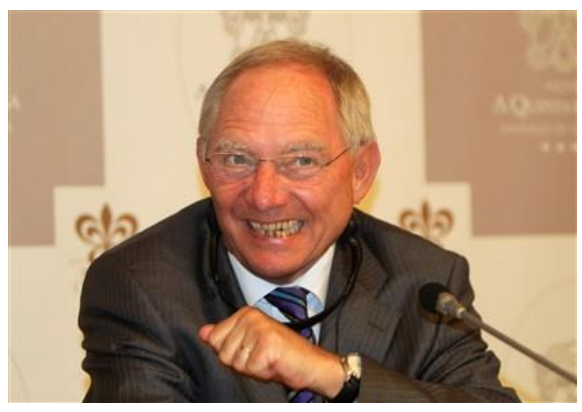

Fonte: "Diário de Notícias" (20.05.2015).

A persuasão e legitimidade invocadas por Hannah Arendt para substituir a força e a violência na política falharam porque a KRISIS pendeu desta vez contra os desapossados, mas a cunha que o SYRIZA cravou na Europa só pode ajudar a facilitar o acesso ao poder aos revolucionários que, de todos os quadrantes, se opõem ao neoliberalismo monolítico (“o pé

\section{POLÊM!CA | Revista Eletronica da Ueij}


está na porta e agora é preciso empurrar"), como diz Mariana Mortágua (deputada do "Bloco de Esquerda") no EXPRESSO de 22.08.2015, ou como canta Leonard Cohen: "there is a crack in everything. That's how the light gets in".

\section{Referências}

ALI, T. The Extreme Centre, a warning. London, N.Y : Verso, 2015.

HUIZINGA, J. Homo Ludens. Lisboa: Edições 70, 2003.

JONES, A. The Establishment: and how they get away with it. London: Penguin Books, 2015.

PEREIRA, H.G. PODEMOS, a emergência de uma nova ferramenta político-social em Espanha. Polêm!ca, v. $15, \mathrm{n}^{\mathrm{o}} 1$, p. 12-28, abril maio e junho 2015.

PERELMAN, C. O império retórico. Retórica e argumentação. Porto: Asa, 1999.

SANTOS, B.S. Fórum social mundial - manual de uso. Porto: Afrontamento, 2005.

SCHUI, F. Austeridade, breve história de um grande erro. Lisboa: Presença, 2014.

SPIVAK, G. Pode o subalterno falar? Belo Horizonte: UFMG, 2010.

VANEIGEM, R. A economia parasitária. Lisboa: Antígona, 2013.

YOULOUNTAS, Y. Exarcheia la noire, au cour de la Grèce qui résiste. St-George-d'Oléron: Les Éditions Libertaires, 2014.

ZIZEK, S. O ano em que sonhámos perigosamente. Lisboa: Relógio d'Água, 2014.

Event, philosophy in transit. London: Penguin Books, 2014.

Recebido em: 29/08/2015.

Aceito em: 01/09/2015. 